\title{
Germinação de sementes de castanheira-do-pará armazenadas em areia úmida
}

\author{
Antonio Nobre da Silva(1), Maria de Fatima Barbosa Coelho(2), Sebastião Carneiro Guimarães(3) \\ e Maria Cristina de Figueiredo e Albuquerque ${ }^{(4)}$
}

\begin{abstract}
(1)Instituto Federal de Ciência e Tecnologia de Mato Grosso, Caixa Postal 244, CEP 78200-000 Cáceres, MT. E-mail: didinobre@gmail.com (2)Universidade Federal Rural do Semi-Árido, Departamento de Ciências Vegetais, Km 47, BR 110, Presidente Costa e Silva, CEP 59625-900 Mossoró, RN. E-mail: coelhomf@ufersa.edu.br ${ }^{(4)}$ Universidade Federal de Mato Grosso, Avenida Fernando Correa da Costa, s/no, CEP $78625-900$ Cuiabá, MT. E-mail: sheep@ufmt.br,mcfa@ufmt.br
\end{abstract}

Resumo - O objetivo deste trabalho foi avaliar o efeito do armazenamento em areia úmida e do pré-tratamento com ácido giberélico na germinação das sementes de castanheira-do-pará. Foram realizados dois experimentos em delineamento experimental de blocos ao acaso, com cinco repetições; o primeiro em viveiro, em arranjo fatorial 4x2, com quatro períodos de armazenamento em areia úmida $(0,90,120$ e 180 dias $)$ e duas concentrações de ácido giberélico ( 0 e $\left.600 \mathrm{mg} \mathrm{L}^{-1}\right)$; o segundo em câmara BOD, em arranjo fatorial 3x2x2: três procedências de sementes, dois substratos - vermiculita e rolo de papel -, e duas concentrações de ácido giberélico - 0 e $600 \mathrm{mg} \mathrm{L}^{-1}$. No primeiro experimento, o armazenamento em areia úmida manteve a viabilidade das sementes, que tiveram de 55 a $64 \%$ de germinação, enquanto o ácido giberélico reduziu a germinação de 82 para 36\%. No segundo, essa redução foi de 98 para $62,5 \%$ e não houve diferença significativa entre procedências e substratos. $\mathrm{O}$ tratamento das amêndoas com ácido giberélico prejudicou o processo germinativo e causou perdas por deterioração. $\mathrm{O}$ armazenamento em areia úmida mantém a viabilidade das sementes de castanheira-do-pará e permite o desenvolvimento do embrião.

Termos para indexação: Bertholletia excelsa, ácido giberélico, conservação, dormência.

\section{Brazil nut seed germination stored in moist sand}

\begin{abstract}
The objective of this work was to evaluate the effects of storage in moist sand and treatment with gibberellic acid on Brazil nut seed germination. Two experiments were carried out in a randomized block design, with five replicates. The first one was done in the nursery, in a factorial $4 \times 2$ arrangement, with four storage periods in moist sand $(0,90,120$ and 180 days) and two concentrations of gibberellic acid ( 0 and $\left.600 \mathrm{mg} \mathrm{L}^{-1}\right)$. The second one was done in a BOD chamber, with a factorial $3 \times 2 \times 2$ arrangement, with three seed origins, two substrata (vermiculite and rolled towel paper), and two concentrations of gibberellic acid ( 0 and $600 \mathrm{mg} \mathrm{L}^{-1}$ ). In the nursery experiment, storage in moist sand maintained seed viability, and germination varied between 55 to $64 \%$, while gibberellic acid caused germination decrease from 82 to $36 \%$. In the BOD chamber, germination was $98 \%$ in the control and $62.5 \%$ with gibberellic acid, and there were no significant differences between origins and substrata. Seed treatment with gibberellic acid decreased germination and caused losses by deterioration. Storage in moist sand maintains the viability of Brazil nut seeds, and embryo maturation may take place.
\end{abstract}

Index terms: Bertholletia excelsa, gibberellic acid, conservation, dormancy.

\section{Introdução}

A castanheira-do-pará (Bertholletia excelsa Bonpl.) é uma espécie arbórea nativa da Amazônia, produtora de sementes oleaginosas e ricas em proteínas de boa qualidade. Após a decadência do ciclo econômico da borracha (Hevea brasiliensis), essa planta constituiuse no principal produto extrativo para exportação dessa região; entretanto, o desmatamento para atender ao avanço da agropecuária tem causado grande impacto nas formações nativas da espécie, com perdas de material genético, exploração direta da madeira e ameaça de extinção. A castanheira-do-pará pode ser considerada como espécie fundamental para aliar a conservação ao desenvolvimento, por ser abundante na região Amazônica, explorada por diversas comunidades no curto prazo e a baixo custo, por apresentar sólida demanda de mercado, além de sua coleta ser de baixo impacto ambiental (Zuidema \& Boot, 2002). 
Em razão da degradação do habitat da castanheira na Amazônia, Salomão et al. (2006) indicaram como estratégia de recuperação desse habitat, a produção de mudas clonadas (enxertadas) com material proveniente das matrizes mais desenvolvidas. Entretanto, o processo de produção de mudas tem uma série de limitações relacionadas à germinação e à conservação de sementes.

As sementes dessa espécie têm comportamento recalcitrante (Camargo 1997), ou seja, são intolerantes à dessecação e a baixas temperaturas - principais formas de conservação de sementes e, portanto, são de difícil armazenamento (Bonjovani \& Barbedo, 2008).

Uma das maiores dificuldades na propagação da castanheira é o processo germinativo lento e desuniforme, contornado, em parte, pela remoção do tegumento lenhoso (Camargo, 1997; Kainer et al., 1999a). Em razão da dificuldade de remover o tegumento, e também porque a germinação estendese por até 180 dias, outros estudos com tratamentos físicos, químicos e mecânicos foram conduzidos por vários autores, porém sem maior progresso (Frazão et al., 1984; Camargo, 1997; Kainer et al., 1999a).

Kainer et al. (1999a) referem-se à possibilidade de existência de dormência química (presença de inibidores) e morfológica (imaturidade do embrião). Camargo (1997) relata que a amêndoa da castanheira, no momento da maturação e dispersão não apresenta tecidos em estádio avançado de diferenciação celular, o que explica, em parte, o lento processo germinativo da espécie. Kainer et al. (1999a) afirmam que o armazenamento úmido aumenta a germinação e permite o desenvolvimento do embrião imaturo e lixivia os inibidores presentes na semente. Em outro artigo, Kainer et al. (1999b) indicam a possibilidade de a germinação lenta e prolongada da castanheira ocorrer em razão da dormência endógena.

As giberelinas são hormônios vegetais com várias funções no processo germinativo de sementes, no crescimento e no desenvolvimento das plantas (Vieira et al., 2002; Stenzel et al., 2003; Lima-Brito et al., 2006; Tokuhisa et al., 2007; Lopes \& Souza, 2008). Podem atuar no crescimento vegetativo do embrião, pelo enfraquecimento da camada de endosperma que envolve e restringe o crescimento desse embrião, e na mobilização de reservas do endosperma (Taiz \& Zeiger, 2004). Assim, tem papel importante na superação da dormência resultante de diversas causas como: embrião imaturo, tegumento duro e presença de inibidores.

O objetivo deste trabalho foi avaliar o efeito do armazenamento em areia úmida e do pré-tratamento com ácido giberélico sobre o processo de germinação das sementes de castanheira-do-pará.

\section{Material e Métodos}

Foram utilizadas sementes de castanheira-do-pará, coletadas em fevereiro de 2007 em três áreas indígenas: Arara do Rio Branco, Zoró e Escondido, localizadas na região noroeste de Mato Grosso. Cada procedência foi considerada como um lote - 1, 2 e 3 -, respectivamente.

Após a coleta, as sementes permaneceram por 65 dias em sacos de ráfia, em condições de viveiro, na Faculdade de Agronomia e Medicina Veterinária, da Universidade Federal de Mato Grosso (UFMT), onde foi feita a seleção, com descarte daquelas com tamanho abaixo de $2,5 \mathrm{~cm}$ e daquelas com danos provocados por fungos. O teor de água das sementes foi determinado em estufa a $105 \pm 3^{\circ} \mathrm{C}$ por 24 horas, em três amostras de 20 sementes, de acordo com as regras para análise de sementes (Brasil, 1992).

No primeiro experimento, foi utilizado o delineamento experimental de blocos ao acaso, em arranjo fatorial $4 \times 2$ (quatro períodos de armazenamento e dois pré-tratamentos), com cinco repetições. Os períodos de armazenamento das sementes em areia úmida foram 0 , 90,120 e 180 dias, seguidos porperíodos complementares de 250, 160, 130 e 70 dias, em ambiente de germinação. Esse ambiente foi composto por caixas de fibra de vidro, com dimensões de 100x100x40 cm, preenchidas com areia lavada, umedecida com água em quantidade suficiente para atingir $60 \%$ da capacidade de retenção. Sempre que necessário, a umidade da areia foi reposta. Durante todo o período, as caixas permaneceram no viveiro, protegidas da chuva por cobertura de plástico colocada a $2 \mathrm{~m}$ de altura. As sementes foram previamente tratadas com os fungicidas Vitavax + Thiram (carboxina $200 \mathrm{~g} \mathrm{~L}^{-1}+$ thiram $200 \mathrm{~g} \mathrm{~L}^{-1}$ ), na proporção de $1: 10$, e depois colocadas dentro de sacolas confeccionadas com tela tipo sombrite, de $60 \times 60 \mathrm{~cm}$ com capacidade de interceptação de $60 \%$ da luz solar diária. Cada sacola continha cerca de 80 sementes $(750 \mathrm{~g})$ entremeadas com areia. As sacolas com sementes devidamente identificadas foram depositadas nas caixas, que 
continham $20 \mathrm{~cm}$ do substrato. Em seguida, as caixas foram preenchidas até a borda superior, de modo que ficasse uma camada de $20 \mathrm{~cm}$ de areia sobre as sementes.

Depois de cada período de armazenamento, as sementes foram retiradas e colocadas em baldes com água; foram descartadas as que flutuavam (chochas) $\mathrm{e}$, depois, foram secas à sombra. Em seguida, foram lixadas na região das estrias do tegumento (quinas), com uso de esmeril elétrico e, posteriormente, as amêndoas foram removidas com a ajuda de canivete. Amêndoas danificadas durante a extração foram descartadas. As amêndoas intactas foram submetidas a dois pré-tratamentos: $0 \mathrm{mg} \mathrm{L}^{-1}$ e $600 \mathrm{mg} \mathrm{L}^{-1}$ de ácido giberélico $\left(\mathrm{GA}_{3}\right)$ durante 48 horas. A unidade experimental foi composta por caixas de plástico com $30 \times 20 \times 9 \mathrm{~cm}$. As amêndoas foram depositadas nas caixas à profundidade de $3 \mathrm{~cm}$ que, posteriormente, foram preenchidas com areia lavada até a borda superior. Em seguida, as amêndoas foram umedecidas com água até atingir $60 \%$ da capacidade de retenção, e novamente umedecidas sempre que necessário. Foram semeadas 20 amêndoas por caixa, mantidas em viveiro coberto com telas com capacidade de interceptação de $60 \%$ da luz solar diária, temperatura entre 27,6 e $33^{\circ} \mathrm{C}$ e umidade relativa do ar média de $60 \pm 5 \%$.

As variáveis avaliadas foram: percentagem de plântula só com raiz $(\mathrm{Ra})$; percentagem de plântulas só com epicótilo (Ep); percentagem de plântulas completas (Ra e Ep); percentagem de plântulas com raiz e/ou com epicótilo (Ra e/ou Ep); percentagem de sementes não germinadas (SNG); e percentagem de sementes deterioradas (SD). Os dados foram submetidos à análise de variância, e as médias foram comparadas pelo teste Scott-Knott, a 5\% de probabilidade (Ferreira, 2000).

No segundo experimento, foram utilizadas sementes dos três lotes, após 180 dias de armazenamento na areia úmida, conforme método descrito anteriormente. $\mathrm{O}$ delineamento experimental foi o de blocos ao acaso, em esquema fatorial $3 \times 2 \times 2$ (três lotes, dois substratos e duas concentrações de $\mathrm{GA}_{3}$ ), com cinco repetições. Os substratos foram vermiculita e papel germiteste na forma de rolo. As concentrações de $\mathrm{GA}_{3}$ foram 0 e $600 \mathrm{mg} \mathrm{L} \mathrm{L}^{-1}$. A unidade experimental foi composta por dez amêndoas, semeadas em caixas de plástico com $16 \times 13 \times 6 \mathrm{~cm}$, preenchidas com vermiculita, ou em rolo de papel germiteste colocado dentro de sacos de plástico. A vermiculita foi umedecida na proporção de $90 \mathrm{~mL}$ de água para cada $30 \mathrm{~g}$, e o papel germiteste com quantidade de água equivalente a 2,5 vezes a sua massa. Os tratamentos foram mantidos em câmara tipo BOD, com temperatura constante de $30^{\circ} \mathrm{C}$.

Após 28 dias, foram avaliadas em percentagem: plântulas só com raiz (Ra), plântulas só com epicótilo (Ep), plântula completa ( $\mathrm{Ra}$ e Ep), plântulas com raiz e/ou com epicótilo ( $\mathrm{Ra}$ e/ou Ep), sementes não germinadas (SNG) e sementes deterioradas (SD). Os dados foram submetidos à análise de variância, e as médias comparadas pelo teste Scott-Knott, a 5\% de probabilidade, com o SISVAR (Ferreira, 2000).

\section{Resultados e Discussão}

As sementes apresentaram teor de água de 14\% antes do armazenamento em areia úmida. Segundo Figueiredo et al. (1990), esse valor é considerado o limite mínimo para a manutenção de vitalidade em castanheira-do-pará. No entanto, após 90 dias de armazenamento, o teor de água aumentou para $27 \%$. Kainer et al. (1999a) observaram aumento no conteúdo de água para 35\%, em sementes de castanheira-do-pará armazenadas em areia úmida por 175 dias.

No primeiro experimento, a interação pré-tratamentos e períodos de armazenamento foi não significativa $(\mathrm{p}>0,05)$ (Tabela 1).

A germinação de sementes pode ser determinada a partir de sementes que apresentam somente radícula, epicótilo, ou radícula e epicótilo (Camargo et al. 2000). Assim, no presente trabalho, quando se considerou a protrusão de qualquer dessas estruturas, verificou-se que o ácido giberélico reduziu a germinação de 82 para $36 \%$. Esses percentuais são altos em comparação

Tabela 1. Percentagem de germinação de sementes de castanheira-do-pará após 0, 90, 120 e 180 dias de armazenamento em areia úmida, complementados com 250, 160, 130 e 70 dias no teste de germinação, em duas concentrações de GA3. Cuiabá, MT, 2007.

\begin{tabular}{lcc}
\hline Características avaliadas & \multicolumn{2}{c}{ Concentração de $\mathrm{GA}_{3}{ }^{(1)}$} \\
\cline { 2 - 3 } & $0 \mathrm{mg} \mathrm{L}$ & $600 \mathrm{mg} \mathrm{L}^{-1}$ \\
\hline Amêndoa com raiz (Ra) & $40 \mathrm{a}$ & $29 \mathrm{~b}$ \\
Amêndoa com epicótilo (Ep) & $1 \mathrm{~b}$ & $2 \mathrm{a}$ \\
Amêndoa com raiz e epicótilo (Ra e Ep) & $41 \mathrm{a}$ & $5 \mathrm{~b}$ \\
Amêndoa com raiz e/ou epicótilo (Ra e/ou Ep) & $82 \mathrm{a}$ & $36 \mathrm{~b}$ \\
Sementes não germinadas (SNG) & $3 \mathrm{~b}$ & $22 \mathrm{a}$ \\
Sementes deterioradas (SD) & $15 \mathrm{~b}$ & $42 \mathrm{a}$ \\
\hline
\end{tabular}

${ }^{(1)}$ Significativo a $5 \%$ de probabilidade pelo teste Scott-Knott. 
aos de Frazão et al. (1984), que observaram variação de 21,5 a $26,75 \%$ em sementes submetidas a diversos pré-tratamentos germinativos. A formação de raiz foi a característica menos sensível à ação do $\mathrm{GA}_{3}$. A protrusão do epicótilo antes da raiz foi muito baixa e está de acordo com o observado por Camargo et al. (2000). O efeito prejudicial do $\mathrm{GA}_{3}$ pode ser comprovado, também, pela percentagem de sementes que não germinaram (22\%) e deterioradas (42\%). $\mathrm{O}$ efeito favorável das giberelinas, na superação da dormência de sementes, é relatado por: Ferronato, (1999), sobre a germinação de sementes de pé-de-anta (Cybistax antisyphilitica); Prado Neto et al. (2007), sobre sementes de jenipapeiro (Genipa americana); Ferreira et al. (2005), sobre sementes de maracujazeiro (Passiflora edulis); Lopes \& Souza (2008), sobre a viabilidade e o vigor de sementes de mamão (Carica papaya); e Bernardes et al. (2008), sobre sementes de pequizeiro (Caryocar brasiliense). No entanto, as giberelinas nem sempre favorecem a germinação e, em alguns casos, podem ter efeito negativo, como nas sementes de Echinacea angustifolia DC. (Macchia et al., 2001), que não foram favorecidas no processo de germinação por esse biorregulador.

$\mathrm{Na}$ Tabela 2, verifica-se que o armazenamento em areia úmida foi eficiente na manutenção da viabilidade das sementes de castanheira-do-pará, uma vez que, na germinação final (presença de raiz e/ou epicótilo), não houve diferença significativa nos períodos avaliados (55 a 64\%). Como os tratamentos consistiram de diferentes proporções entre número de dias no armazenamento e número de dias no teste de germinação, essa semelhança nos períodos avaliados pode indicar que tanto o ambiente de armazenamento quanto o de germinação forneceram as condições para que as sementes de castanheira-do-pará evoluíssem nos processos de diferenciação e, posteriormente, crescimento do eixo embrionário, o que culminou com a protrusão da raiz ou do epicótilo. Kainer et al. (1999a) também verificaram este comportamento em sementes armazenadas em areia úmida, mas aventaram a hipótese de dormência exógena. Entretanto, no presente trabalho, o teste de germinação foi conduzido com a amêndoa sem o tegumento e, portanto, a dormência deve ser endógena.

Várias sementes completaram o processo de germinação, ainda durante o armazenamento (Tabela 2) aos: 120 dias, $20,8 \%$ no lote $1 ; 180$ dias, $23,3 \%$ no lote $1,12,8 \%$ no lote 2 e $1,65 \%$ no lote 3 . Essas sementes foram excluídas da amostra destinada ao teste de germinação; assim, os embriões que estavam em fase mais adiantada no processo de diferenciação do eixo embrionário foram excluídos dos lotes. Quando se prolongou o período de armazenamento, ocorreu redução na percentagem de plântulas completas e aumento na percentagem daquelas que só produziram raiz. Esse fato foi mais evidente no maior período de armazenamento, que foi de 180 dias. Embora, tanto no armazenamento quanto no teste de germinação, as sementes tenham permanecido enterradas em areia úmida, o tamanho das caixas e a altura da camada de areia sobre as sementes eram diferentes, e se constituíram, portanto, ambientes distintos. No ambiente de armazenamento, ocorreu menos oscilação no teor de água e na temperatura que estava, em média, $3,5^{\circ} \mathrm{C}$ mais baixa. Temperaturas obtidas no interior da areia úmida, na profundidade média de colocação das sementes, atingiram valores de $24,1^{\circ} \mathrm{C}$, no ambiente de armazenamento, e $26^{\circ} \mathrm{C}$ no ambiente de germinação (BOD). Assim, diferenciação e crescimento do eixo embrionário, embora pudessem ocorrer nos dois ambientes, apresentaram velocidades distintas. Kainer et al. (1999a) não verificaram germinação de sementes de castanheira-do-pará durante os 175 dias

Tabela 2. Percentagem de germinação de castanheira-do-pará após 0, 90, 120 e 180 dias de armazenamento em areia úmida, complementados com 250, 160, 130 e 70 dias no teste de germinação (médias dos dois pré-tratamentos com ácido giberélico). Cuiabá-MT, 2007.

\begin{tabular}{|c|c|c|c|c|c|}
\hline \multirow{2}{*}{$\begin{array}{l}\text { Período de armazenamento/teste } \\
\text { de germinação (dias) }\end{array}$} & \multicolumn{3}{|c|}{ Percentagem de germinação ${ }^{(1)^{*}}$} & \multirow[t]{2}{*}{$\mathrm{SNG}^{(2)^{*}}$} & \multirow[t]{2}{*}{$\mathrm{SD}^{(3)^{*}}$} \\
\hline & $\mathrm{Ra}$ & $\mathrm{Ra}$ e/ou Ep & Ra e Ep & & \\
\hline $0 / 250$ & $25 b$ & $55 \mathrm{a}$ & $30 \mathrm{a}$ & $37 \mathrm{a}$ & $8 \mathrm{~b}$ \\
\hline $90 / 160$ & $24 b$ & $57 \mathrm{a}$ & $30 \mathrm{a}$ & $10 \mathrm{~b}$ & $33 \mathrm{a}$ \\
\hline $120 / 130$ & $33 b$ & $58 \mathrm{a}$ & $24 \mathrm{a}$ & $11 b$ & $31 \mathrm{a}$ \\
\hline $180 / 70$ & $48 \mathrm{a}$ & $64 \mathrm{a}$ & $15 \mathrm{~b}$ & $13 b$ & $23 \mathrm{a}$ \\
\hline
\end{tabular}

${ }^{(1)} \mathrm{Ra}$, amêndoa com raiz; Ra e/ou Ep, amêndoa com raiz, amêndoa com epicótilo e com raiz e epicótilo; Ra e Ep, amêndoa com raiz e epicótilo. ${ }^{(2)} \mathrm{SNG}$, sementes não germinadas. ${ }^{(3)} \mathrm{SD}$, sementes deterioradas. *Médias seguidas de letras iguais não diferem entre si pelo teste Scott-Knott, a 5\% de probabilidade. 
de armazenamento em areia úmida. O material genético usado por esses autores foi proveniente de sementes de dez árvores, em Xapuri no Acre, e o comportamento germinativo no armazenamento úmido foi diferente entre as famílias. Como as condições de armazenamento úmido, no presente trabalho, foram as mesmas usadas por Kainer et al. (1999a), as diferenças entre os resultados podem ter sido ocasionadas pela diferente origem das sementes.

O armazenamento (Tabela 2) não alterou a taxa de germinação ou deterioração das sementes, mas a percentagem de sementes não germinadas foi elevada em sementes não armazenadas, o que é uma evidência da eficiência do armazenamento em areia úmida, para que se complete o desenvolvimento do embrião imaturo.

A percentagem de sementes deterioradas foi maior em sementes armazenadas, o que difere dos resultados obtidos por Kainer et al. (1999a), que observaram $46,5 \%$ de sementes deterioradas, em sementes não armazenadas, e $26,2 \%$ em sementes armazenadas. Entretanto, na comparação dos períodos de armazenamento, verifica-se que a percentagem de sementes deterioradas variou de 23 a $33 \%$, sem diferença significativa entre as médias, e que esses valores estão próximos dos $26,2 \%$ obtidos por Kainer et al. (1999a).

No segundo experimento, o único fator que apresentou efeito significativo na análise de variância foi o pré-tratamento, portanto, os dados apresentados são médias de lotes e de substratos (Tabela 3).

A protrusão de raiz primária ocorreu sete dias após a semeadura e, aos 28 dias, já foram observados os valores médios de 69,7 e $55 \%$ de sementes com raiz, para as doses $0 \mathrm{mg} \mathrm{L}^{-1}$ e $600 \mathrm{mg} \mathrm{L}^{-1}$ de $\mathrm{GA}_{3}$, respectivamente, sem diferença estatística entre elas. Esses valores são semelhantes aos verificados no primeiro experimento,

Tabela 3. Percentagem de germinação de castanheira-do-pará, aos 28 dias após a semeadura, média de três procedências ${ }^{(1)} \mathrm{e}$ dois substratos $^{(2)}$. Cuiabá-MT, 2007.

\begin{tabular}{lcc}
\hline Características avaliadas & \multicolumn{2}{c}{ Concentração de ácido giberélico ${ }^{(3)}$} \\
\cline { 2 - 3 } & $0 \mathrm{mg} \mathrm{L}^{-1}$ & $600 \mathrm{mg} \mathrm{L}^{-1}$ \\
\hline Amêndoa com raiz (Ra) & $69,7 \mathrm{a}$ & $55,0 \mathrm{a}$ \\
Amêndoa com epicótilo (Ep) & $28,3 \mathrm{a}$ & $7,5 \mathrm{~b}$ \\
Sementes não germinadas (SNG) & $1,0 \mathrm{~b}$ & $27,0 \mathrm{a}$ \\
Sementes deterioradas (SD) & $1,0 \mathrm{~b}$ & $10,5 \mathrm{a}$ \\
\hline
\end{tabular}

${ }^{(1)}$ Arara do Rio Branco, Zoró e Escondido, terras indigenas a noroeste de Mato Grosso. ${ }^{(2)}$ Vermiculita e papel germiteste. ${ }^{(3)}$ Médias seguidas de letras iguais, nas linhas, não diferem entre si pelo teste Scott-Knott, a 5\% de probabilidade. mas foram obtidos com menos tempo de incubação. $\mathrm{O}$ controle da temperatura, mantida a $30^{\circ} \mathrm{C}$, foi o fator de maior distinção entre os ensaios. Nesse período de avaliação, não houve formação de plântulas completas (com raiz e epicótilo). A germinação expressa como percentagem de plântulas, com raiz primária ou com epicótilo, foi de $98 \%$ no tratamento testemunha e $62,5 \%$ nas sementes pré-tratadas com $600 \mathrm{mg} \mathrm{L}^{-1} \mathrm{de} \mathrm{GA}_{3}$. Essa germinação elevada assegura que os lotes de sementes utilizados tinham alta percentagem de sementes viáveis. Também é indicação de que temperaturas constantes de $30^{\circ} \mathrm{C}$ podem favorecer a velocidade do processo de germinação. $\mathrm{O}$ pré-tratamento com ácido giberélico proporcionou maior percentagem de sementes não germinadas e de sementes deterioradas.

Assim, a técnica de armazenamento de sementes de castanheira-do-pará em areia úmida, além de conservar as sementes, possibilita a continuidade do processo de formação do embrião. Para o manejo em viveiros esse fato é importante, pois durante seis meses as sementes podem ficar armazenadas em areia úmida, em condições de temperatura ambiente $\left(27\right.$ a $\left.33^{\circ} \mathrm{C}\right)$, sem perder a viabilidade.

\section{Conclusões}

1. O armazenamento em areia úmida mantém a viabilidade das sementes de castanheira-do-pará e possibilita o desenvolvimento do embrião.

2. O tratamento das amêndoas com ácido giberélico prejudica o processo germinativo e causa perdas por deterioração.

\section{Referências}

BERNARDES, T.G.; NAVES, R.V.; REZENDE, C.F.A.; BORGES, J.D.; CHAVES, L.J. Propagação sexuada de pequizeiro (Caryocar brasiliense Camb.) estimulada por ácido giberélico. Pesquisa Agropecuária Tropical, v.38, p.71-77, 2008.

BONJOVANI, M.R.; BARBEDO, C.J. Sementes recalcitrantes: intolerantes a baixas temperaturas? Embriões recalcitrantes de Inga vera Willd. subsp. affinis (DC.) T. D. Penn. toleram temperatura sub-zero. Revista Brasileira de Botânica, v.31, p.345-356. 2008.

BRASIL. Ministério da Agricultura e Reforma Agrária. Regras para análise de sementes. Brasília: MDA, 1992. 365p.

CAMARGO, I.P. de. Estudos sobre a propagação da castanheira-do-brasil (Bertholletia excelsa Humb. \& Bompl.). 1997. 126p. Tese (Doutorado) - Universidade Federal de Lavras, Lavras. 
CAMARGO, I.P. de; CASTRO, E.M. de; GAVILANES, M.L. Aspectos da anatomia e morfologia de amêndoas e plântulas de castanheira-do-brasil. Cerne, v.6, p.11-18, 2000.

FERREIRA, D.F. Manual do sistema Sisvar para análise estatística. Lavras: UFLA, 2000. 63p.

FERREIRA, G.; OLIVEIRA, A. de; RODRIGUES, J.D.; DIAS, G.B.; DETONI, A.M.; TESSER, S.M.; ANTUNES, A.M. Efeito de arilo na germinação de sementes de Passiflora alata Curtis em diferentes substratos e submetidas a tratamentos com giberelina. Revista Brasileira de Fruticultura, v.27, p.277-280, 2005.

FERRONATO, A. Análise de sementes de Bowdichia virgilionides H.B.K (sucupira-preta) e Cybistax antisyphilitica M. (pé-de-anta). 1999. 80p. Dissertação (Mestrado) - Universidade Federal de Mato Grosso, Cuiabá.

FIGUEIREDO, F.J.C.; CARVALHO, J.E.U. de; FRAZÃO, D.A.C. Nível crítico de umidade de sementes e seus efeitos sobre a emergência de plântulas de castanha-do-brasil. Belém: Embrapa-CPATU, 1990. 17p. (Embrapa-CPATU. Boletim de Pesquisa, 113).

FRAZÃO, D.A.C.; MÜLlER, C.H.; FIGUEIREDO, F.J.C.; MULLER, A.A.; PEREIRA, L.A.F. Escarificação química na emergência de sementes de castanha-do-brasil (Bertholletia excelsa, H.B.K.). Revista Brasileira de Sementes, v.6, p.83-90, 1984.

KAINER, K.A.; DURYEA, M.L.; MALAVASI, M. de M.; SILVA, A.R. da; HARRISON, J. Moist storage of Brazil nut seeds for improved germination and nursery management. Forest Ecology and Management, v.116, p.207-217, 1999a.

KAINER, K.A.; MALAVASI, M.D.; DURYEA, M.L.; SILVA, E. Brazil nut (Bertholletia excelsa) seed characteristics, preimbibition and germination. Seed Science and Technology, v.27, p.731-745, 1999b.

LIMA-BRITO, A.; CAMPOS, V.C.A.; SANTANA, J.R.F.; DORNELES, A.L.C. Efeito do acido giberélico $\left(\mathrm{GA}_{3}\right)$ na emergência de plântulas de Annona crassiflora Mart., Annona squamosa L. e Annona muricata L. Magistra, v.18, p.27-33, 2006.

LOPES, H.M.; SOUZA, C.M. Efeitos da giberelina e da secagem no condicionamento osmótico sobre a viabilidade e o vigor de sementes de mamão (Carica papaya L.). Revista Brasileira de Sementes, v.30, p.181-189. 2008.

MACCHIA, M.; ANGELINI, L.G.; CECCARINI, L. Methods to overcome seed dormancy in Enchinacea angustifolia DC. Scientia Horticulturae, v.89, p.317-324, 2001.

PRADO NETO, M.; DANTAS, A.C.V.L.; VIEIRA, E.L; ALMEIDA, V. de O. Germinação de sementes de jenipapeiro submetida a pré-embebição em regulador e estimulante vegetal. Ciência Agrotécnica, v.31, p.693-698, 2007.

SALOMÃO, R. de P.; ROSA, N.A.; CASTILHO, A.; MORAIS, K.A.C. Castanheira-do-brasil recuperando áreas degradadas e provendo alimento e renda para comunidades da Amazônia Setentrional. Boletim do Museu Paraense Emílio Goeldi, v.1, p.65-78, 2006.

STENZEL, N.M.C.; MURATA, I.M.; NEVES, C.S.V.J. Superação da dormência em sementes de atemóia e fruta-do-conde. Revista Brasileira de Fruticultura, v.25, p.305-308, 2003.

TAIZ, L.; ZEIGER, E. Fisiologia vegetal. Porto Alegre: Artmed, 2004. 786p.

TOKUHISA, D.; DIAS, D.C.F. dos S.; ALVARENGA, E.M.; DIAS, L.A. dos S.; MARIN, S.L.D. Tratamentos para superação da dormência em sementes de mamão. Revista Brasileira de Sementes, v.29, p.131-139, 2007.

VIEIRA, A.R.; VIEIRA, M. das G.G.C.; FRAGA, A.C.; OLIVEIRA, J.A.; SANTOS, C.D. dos. Action of gibberellic acid $\left(\mathrm{GA}_{3}\right)$ on dormancy and activity of a-amylase in rice seeds. Revista Brasileira de Sementes, v.24, p.43-48, 2002.

ZUIDEMA, P.A.; BOOT, R.G.A. Demography of the Brazil nut tree (Bertholletia excelsa) in the Bolivian Amazon: impact of seed extraction on recruitment and population dynamics. Journal of Tropical Ecology, v.18, p.1-31, 2002.

Recebido em 23 de junho de 2009 e aprovado em 29 de outubro de 2009 